\title{
Use of Extra-Narrow-Diameter Implants in Reduced Alveolar Ridge: A Case Report
}

\section{Camila Ferreira Mattos ${ }^{*}$, Marco Antônio Alencar De Carvalho' ${ }^{1}$, Jorge José De Carvalho², Paulo Gonçalo Pinto Dos Santos¹, Jorge Luis Da Silva Pires'1, Igor Da Silva Brum¹}

\author{
${ }^{1}$ Department of Implantology, Faculty of Dentistry, State University of Rio de Janeiro, Rio de Janeiro, Brazil \\ ${ }^{2}$ Department of Biology, Faculty of Dentistry, State University of Rio de Janeiro, Rio de Janeiro, Brazil \\ Email: `mattocamila@gmail.com, odontogermac@uol.com.br, jjcarv@gmail.com,pgps@domain.com.br, \\ jorgepires45@gmail.com, Igorbrum1@hotmail.com
}

How to cite this paper: Ferreira Mattos, C., Alencar De Carvalho, M.A., De Carvalho, J.J., Pinto Dos Santos, P.G., Da Silva Pires, J.L. and Da Silva Brum, I. (2020) Use of Extra-Narrow-Diameter Implants in Reduced Alveolar Ridge: A Case Report. Journal of Biomaterials and Nanobiotechnology, 11, 101-109.

https://doi.org/10.4236/jbnb.2020.112007

Received: February 11, 2020

Accepted: March 15, 2020

Published: March 18, 2020

Copyright $\odot 2020$ by author(s) and Scientific Research Publishing Inc. This work is licensed under the Creative Commons Attribution International License (CC BY 4.0).

http://creativecommons.org/licenses/by/4.0/

\begin{abstract}
Background: Narrow-diameter implants (3.0 - $3.5 \mathrm{~mm}$ range) have been introduced for the replacement of teeth with insufficient bone structure and/or limited mesiodistal or interimplant spaces, and appear to offer clinical results similar to those obtained with implants of greater diameter. Studies using extra-narrow-diameter implants $(2.8 \mathrm{~mm})$ are scarce. Case Presentation: A 59-year-old male patient received two extra-narrow-diameter implants, $2.8 \times$ $11 \mathrm{~mm}$ in the region between elements 11 and 14 . Together, two $3.5 \times 8.5 \mathrm{~mm}$ SYSTHEX ${ }^{\circledR}$ platform 4.1 implants were installed in the region of elements 15 and 16 to provide greater stability in the occlusion. Of four previous implants on the maxillary left side, one in the region between the elements 23 and 24 that was located in a very apical position and vestibularized was removed. The provisional was already installed on the elements 11,21 , and 22 with the metal cores already prepared and with the Globteck ${ }^{\otimes}$ implants in the region of the elements 23,24, and 27. The functional and esthetic results were satisfactory. Conclusions: Insertion of extra-narrow-diameter implants of $2.8 \mathrm{~mm}$ in the maxillary anterior region is a reliable option in a patient with absence of elements 12 and 13, restoring masticatory function and aesthetics in the upper arch.
\end{abstract}

\section{Keywords}

Dental Implants, Narrow-Diameter, Maxilla, Bone Density

\section{Background}

Narrow-diameter implants have been introduced for the replacement of teeth with insufficient bone structure in the bone crest and/or limited mesiodistal or 
interimplant spaces, such as in the upper lateral or lower incisors areas, and are claimed to be a reasonable alternative to bone augmentation procedures [1] [2] [3]. These implants are associated with high survival rates, favorable marginal bone loss, and increased satisfaction and quality of life of patients [4]. Narrow implants are generally subdivided into implants with diameter of less than 3.0 $\mathrm{mm}$ classified as extra-narrow-diameter, and with diameter equal to or more than $3.0 \mathrm{~mm}$ and less than $3.75 \mathrm{~mm}$ classified as narrow-diameter implants. In a study of narrow-diameter $(3.5 \mathrm{~mm})$ implants replacing either a central or a lateral incisor in the maxilla, follow-up examinations up to 3 years after loading showed successful results and margin bone loss following the same pattern than in standard diameter $(3.75 \mathrm{~mm})$ implants [5]. The diameter of a dental implant is selected based on the type of edentulousness, the amount of the residual bone, the space volume available for the prosthetic rehabilitation, the emergency profile, and the type of occlusion [6]. On the other hand, given the challenges of rehabilitation in edentulous patients for the use of implants in regions where there is bone insufficiency, the use of narrow-diameter implants without the need of complementary surgeries to increase the amount of bone, makes treatment less costly and traumatic in the preparatory period [7]. It is also important to consider the mesiodistal dimension of the prosthetic space, since an adequate distance between the teeth and implants is necessary to reduce subsequent bone resorption in the papilla region, with an external hexagon interface of $3 \mathrm{~mm}$ between implants and cone morse of $1.5 \mathrm{~mm}$ between implants. Therefore, in order to preserve these characteristics, in many cases, it is necessary to use extra-narrow-diameter implants such as those of $2.8 \mathrm{~mm}$, which allows for oral rehabilitation while respecting the functional spaces [8] [9].

The purpose of this study is to describe a case report as an example of how rehabilitation is possible in a patient with absence of elements 12 and 13 using extra-narrow-diameter implants of $2.8 \mathrm{~mm}$ diameter. Because the clinical experience with extra-narrow-diameter implants is limited, we also intended to present this case to show the applicability and success of using extra-narrow-diameter implants in daily oral implantology practice.

\section{Case Presentation}

A 59-year-old male patient attended a specialization course in Implant Dentistry at the Faculty of Dentistry of the State University of Rio de Janeiro, Rio de Janeiro (Brazil) seeking to restore its masticatory function and aesthetics in the upper arch. He reported having undergone various treatments along the previous months, which were unsuccessful to achieve satisfactory implant rehabilitation. In the clinical and radiographic examination four implants (Globteck, Bethaville SP, Brazil) were observed on the maxillary left side, with the implant area of element 23 placed protuberantly and in a more apical position as compared to the remaining implants (Figure 1). All possibilities of rehabilitation were considered based on results of panoramic radiographs, periapical radiographs, and computed tomography (CT) studies, as well as analysis in semi-adjustable articulators to 
check for occlusion of the arcades. Once a correct and comfortable occlusion for the patient was determined, diagnostic waxing was done to simulate the position of the implant supported teeth to achieve the desired esthetics and function.

The implant in the region between the elements 23 and 24 that was completely outside the ideal positioning for the placement of a functional crown, located in a very apical position and vestibularized was removed. As shown in CT studies, type III bone with little thickness prevented to place a $3.5 \mathrm{~mm}$ implant. Therefore, two narrow-diameter implants, $2.8 \times 11 \mathrm{~mm}$ (SYSTHEX Implantes Dentários, Curitiba, Brazil) in the region between elements 11 and 14 (Figure 2) were placed instead of a fixed bridge of four elements in the edentulous space between elements 11 and 14, as these would be better in biomechanics, and besides esthetics, the required space was insufficient for the placement of two lateral and canine incisor crowns (Figure 3). Together, two $3.5 \times 8.5 \mathrm{~mm}$ SYSTHEX ${ }^{\oplus}$ platform 4.1 implants were installed in the region of elements 15 and 16 , to provide greater stability in the occlusion, in addition to returning the canine and group guides.

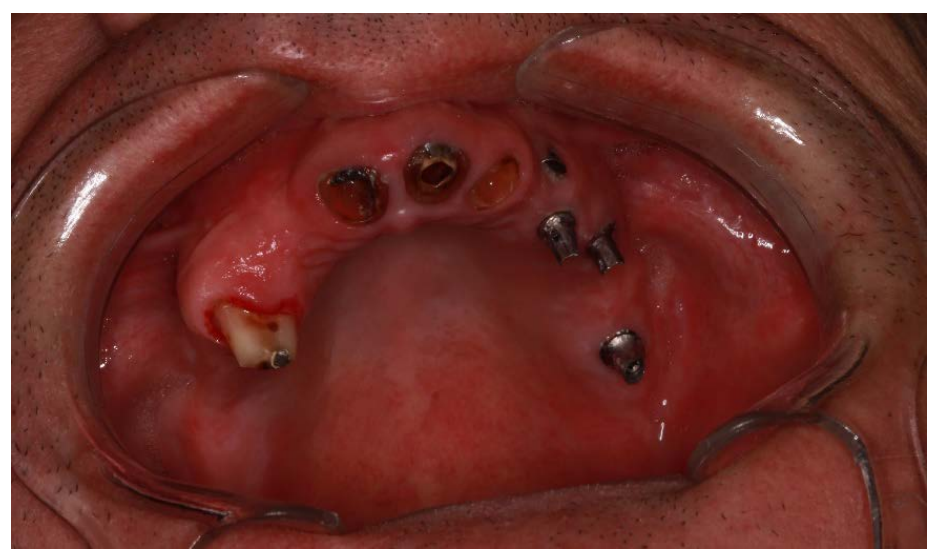

Figure 1. A previous implant in the area of element 23 in a more apical position and vestibulized as compared with the other implants.

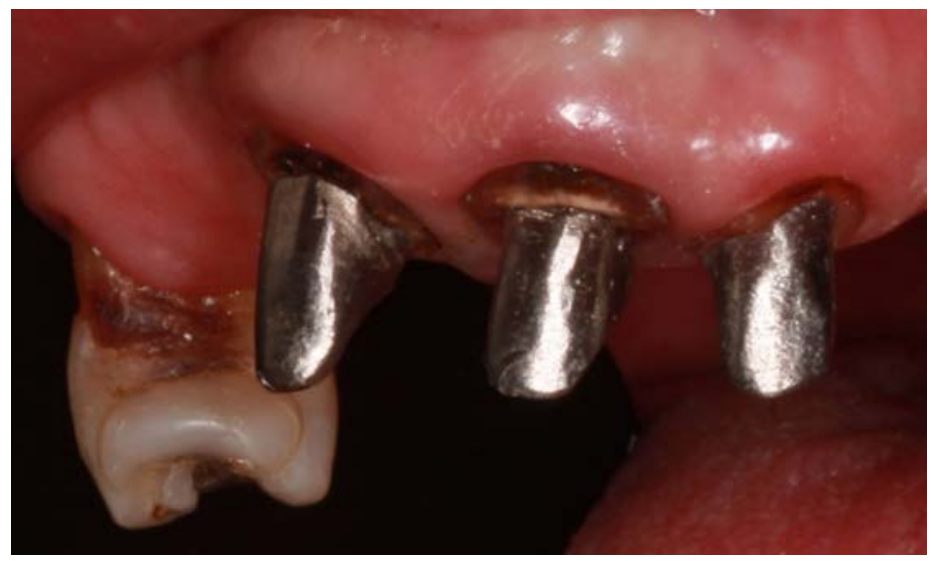

Figure 2. Narrow diameter platform implants installed in the region between elements 11 and 14. 
The conduits of elements 21,22 , and 11 were properly prepared and received metal pin and core (Figure 4). Figure 5 shows the provisional already installed on the elements 11,21 , and 22 with the metal cores already prepared and with the Globteck ${ }^{\circledast}$ implants in the region of the elements 23,24 , and 27 . Such a provisional one gave an improvement which was initially esthetic, which pleased the patient, who did not smile much, and began to chew more harmonically. These implants were long without mechanical load and needed to be put into function.

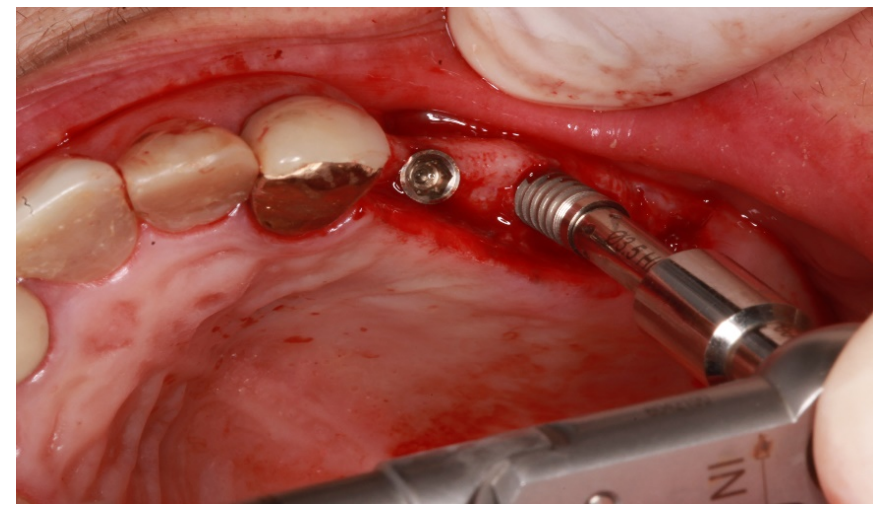

Figure 3. Insufficient space for placement of three elements.

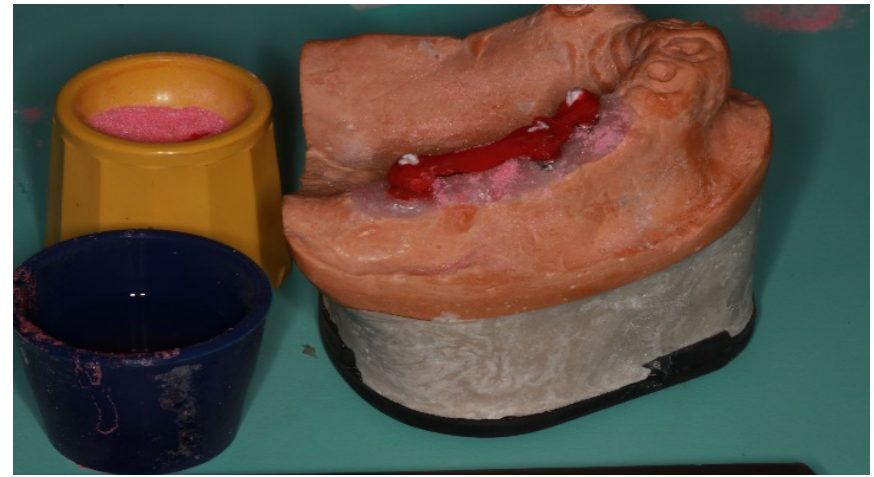

Figure 4. Elements 21, 22 and 11 with metal pin and core prepared for the definitive crown.

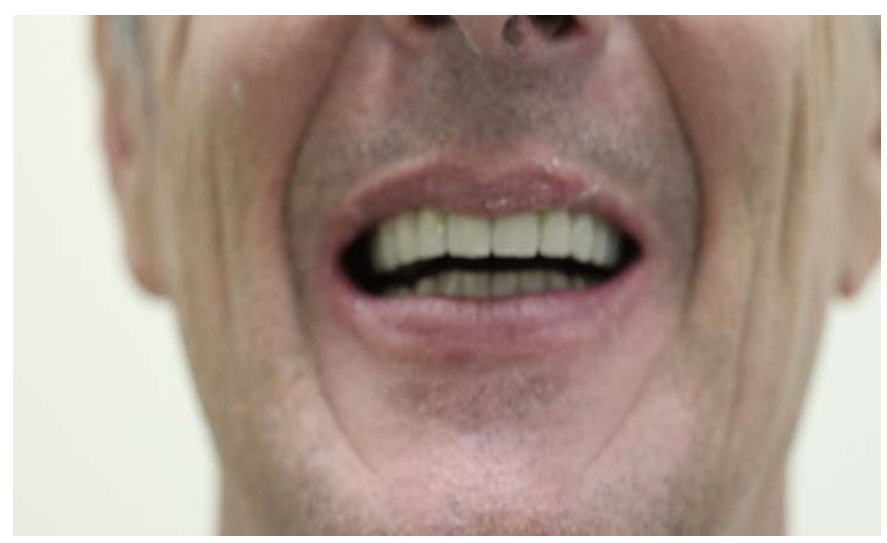

Figure 5. Provisional elements 21, 22 and 11 already installed with satisfactory esthetic appearance and function. 


\section{Discussion}

The present clinical case illustrates that extra-narrow-diameter implants can be successfully used to restore esthetics and function of missing maxillary teeth. The replacement of lost natural teeth by means of tissue-integrated implants represents a major advance in clinical treatment. The genesis of osseointegration, a concept introduced by Brånemark in the 1960s [10] has widened the scope of treatment options for edentulous patients, making feasible and extending the treatment to areas of partial edentulism [11]. Generally, the use of standard diameter or large diameter implants is recommended in order to ensure adequate bone-implant contact, with a space of $2-3 \mathrm{~mm}$ between the implant surface and the natural collateral root surface. However, the smaller mesiodistal diameter of certain anterior teeth or the thinness of the bony ridge does not always allow for such implants to be placed. In these circumstances, narrow-diameter implants have been shown to be an effective option.

Delgado et al. [12] evaluated the insertion torque, the amount of deformation, and the characteristic pattern of distortion experienced by narrow dental implants $(3.3 \mathrm{~mm}$ and $3.5 \mathrm{~mm}$ ) and different internal connections designs after their insertion in artificial Type II bone, concluding that correct implant handling and proper implant bed preparation are essential to a reduction in deformation and the release of titanium particles in the implant index during the insertion of narrow implants. With the introduction of grade 5 titanium implants is was possible to reduce deformation and to achieve more predictability in the long-term results of oral rehabilitation using narrow implants [13]. In a study of 40 patients requiring a single-implant crown in the anterior or premolar regions, titanium-zirconium $3.3 \mathrm{~mm}$ diameter implants not differ from titanium $4.1 \mathrm{~mm}$ diameter regarding the clinical performance over a 3-year period [14]. Moreover, in a comparison of two commercially available narrow-diameter implants, 3.5 and $2.9 \mathrm{~mm}$, for their performances under axial and oblique loading in simulated situations of all-on-4 treatment, both implants showed a similar biomechanical behavior [15]. However, despite a lower risk of peri-implant bone loss, the 3.5-mm model had higher peak stress on implants and abutments than the 2.9-mm model [15]. Thus, narrow implants up to $2.8 \mathrm{~mm}$ in diameter are not associated with any structural risk as compared to standard diameter implants [16].

A number of studies published in the literature have provided evidence of the usefulness of narrow-diameter implants in different clinical indications compared to standard diameter implants [6] [17] [18] [19] [20]. Also, narrow-diameter implants could be considered for use with fixed restorations and mandibular overdentures, since their success rate appears to be comparable to that of regular diameter implants [21]. Arisan et al. [22] performed a study to evaluate clinical outcome, success and survival rates, changes in bone level, mechanical and prosthetic complications after loading of the narrow implants through clinical follow-up for 5 - 10 years. They concluded that narrow implants 
can be used with confidence where a regular diameter implant is not convenient. The loss of marginal bone in narrow implants occurred predominantly during the two years of loading and after that period the loss was minimal.

Both implants with a reduced diameter (between 3 and $3.5 \mathrm{~mm}$ ) and implants with an extra-small diameter $(<3 \mathrm{~mm})$ have been used in definitive rehabilitation treatments in the anterior maxilla and mandible, and are available in 2 (implant and prosthetic component) and can be loaded conventionally or immediately. In our patient, two extra-narrow-diameter implants of $2.8 \mathrm{~mm}$ diameter were placed between elements 11 and 14 because type III bone with little thickness prevented to place a $3.5 \mathrm{~mm}$ implant.

Narrow-diameter implants have been used to restore limited spaces in the anterior esthetic zones. In a consecutive case series with 3 to 14 years follow-up, 19 narrow-diameter implants placed in 14 patients, no implant failures or prosthetic complications were reported, yielding a $100 \%$ survival rate and an $84.2 \%$ success rate, with all patients reporting that they were very satisfied with the esthetic results [23]. A clinical and radiological follow-up of narrow-diameter implants (3.0 - $3.3 \mathrm{~mm}$ ) replacing maxillary laterals and mandibular incisors, good function and implant survival of $97.2 \%$ was reported, but the two main patient concerns were discoloration and regression of the buccal gingiva [24]. In a meta-analysis of 29 studies with 3048 narrow-diameter implants ( 3.0 and $3.25 \mathrm{~mm}$ ), satisfactory survival rates of around $95 \%$ and little marginal bone resorption of around $0.5 \mathrm{~mm}$ after a mean follow-up of 3 years were found [25]. In addition, a meta-analysis of 892 narrow-diameter implants placed in the anterior region in 736 patients, with a mean follow-up of 40 months, showed a mean success rate of $95.2 \%$ [26]. On the other hand, surface characteristics (TiUnite) have been identified as a risk factor for failure in narrow-diameter implants in the maxillary anterior region [27].

\section{Conclusion}

The findings of the present case indicate that insertion of extra-narrow-diameter implants of $2.8 \mathrm{~mm}$ in the maxillary anterior region is a reliable option in a patient with absence of elements 12 and 13, restoring masticatory function and aesthetics in the upper arch.

\section{Acknowledgements}

The authors thank Marta Pulido, MD, PhD, for editing the manuscript and editorial assistance.

\section{Authors' Contributions}

CFM performed the review of the literature, the data collection and writing of the article. MAAC, PGPS, ISB, and JLSP performed surgery and treated the patient, and a review of the article. JJC performed a review of the article and orientation of the work. All authors read and approved the final manuscript. 


\section{Funding}

None.

\section{Availability of Data and Materials}

Data sharing is not applicable to this article as no datasets were generated or analyzed during the current study.

\section{Ethics Approval and Consent to Participate}

The requirements of good clinical practice were observed, and the patient gave informed consent for surgical and rehabilitation procedures.

\section{Conflicts of Interest}

Authors C. Ferreira Mattos, M.A. Alencar de Carvalho, J.J. De Carvalho, P.G. Pinto dos Santos, I. da Silva Brum, J.L. da Silva Pires states there are no conflicts of interest.

\section{Consent for Publication}

Not applicable.

\section{References}

[1] Schiegnitz, E. and Al-Nawas, B. (2018) Narrow-Diameter Implants: A Systematic Review and Meta-Analysis. Clinical Oral Implants Research, 29, 21-40. https://doi.org/10.1111/clr.13272

[2] Marcello-Machado, R.M., Faot, F., Schuster, A.J., Nascimento, G.G. and Del Bel Cury, A.A. (2018) Mini-Implants and Narrow-Diameter Implants as Mandibular Overdenture Retainers: A Systematic Review and Meta-Analysis of Clinical and Radiographic Outcomes. Journal of Oral Rehabilitation, 45, 161-183. https://doi.org/10.1111/joor.12585

[3] Lemos, C.A., Verri, F.R., Batista, V.E., Júnior, J.F., Mello, C.C. and Pellizzer, E.P. (2017) Complete Overdentures Retained by Mini Implants: A Systematic Review. Journal of Dentistry, 57, 4-13. https://doi.org/10.1016/j.jdent.2016.11.009

[4] Aunmeungtong, W., Kumchai, T., Strietzel, F.P., Reichart, P.A. and Khongkhunthian, P. (2017) Comparative Clinical Study of Conventional Dental Implants and Mini Dental Implants for Mandibular Overdentures: A Randomized Clinical Trial. Clinical Implant Dentistry and Related Research, 19, 328-340. https://doi.org/10.1111/cid.12461

[5] Andersen, E., Saxegaard, E., Knutsen, B.M. and Haanaes, H.R. (2001) A Prospective Clinical Study Evaluating the Safety and Effectiveness of Narrow-Diameter Threaded Implants in the Anterior Region of the Maxilla. The International Journal of Oral \& Maxillofacial Implants, 16, 217-224.

[6] Davarpanah, M., Martinez, H., Tecucianu, J.F., Celletti, R. and Lazzara, R. (2000) Small-Diameter Implants: Indications and Contraindications. Journal of Esthetic Dentistry, 12, 186-194. https://doi.org/10.1111/j.1708-8240.2000.tb00221.x

[7] Carlsson, G.E. and Omar, R. (2010) The Future of Complete Dentures in Oral Rehabilitation. A Critical Review. Journal of Oral Rehabilitation, 37, 143-156. 
https://doi.org/10.1111/j.1365-2842.2009.02039.x

[8] Tarnow, D.P., Cho, S.C. and Wallace, S.S. (2000) The Effect of Inter-Implant Distance on the Height of Inter-Implant Bone Crest. Journal of Periodontology, 71, 546-549. https://doi.org/10.1902/jop.2000.71.4.546

[9] Corcuera-Flores, J.R., Pérez-Fierro, M., Blanco-Carrión, A., Torres-Lagares, D., Castellanos-Cosano, L. and Machuca-Portillo, G. (2020) Bone Loss around Narrow Implants versus Standard Diameter Implants: Retrospective 2-Years Case-Control Study. Journal of Clinical and Experimental Dentistry, 12, e79-e84. https://doi.org/10.4317/jced.56422

[10] Brånemark, P.I., Adell, R., Breine, U., Hansson, B.O., Lindström, J. and Ohlsson, A. (1969) Intra-Osseous Anchorage of Dental Prostheses. I. Experimental Studies. Scandinavian Journal of Plastic and Reconstructive Surgery, 3, 81-100. https://doi.org/10.3109/02844316909036699

[11] Jayesh, R.S. and Dhinakarsamy, V. (2015) Osseointegration. Journal of Pharmacy and Bioallied Sciences, 7, S226-S229. https://doi.org/10.4103/0975-7406.155917

[12] Delgado-Ruiz, R., Silvente, A.N. and Romanos, G. (2019) Deformation of the Internal Connection of Narrow Implants after Insertion in Dense Bone: An in Vitro Study. Materials, 12, 1833. https://doi.org/10.3390/ma12111833

[13] Salvi, G.E. and Lang, N.P. (2001) Changing Paradigms in Implant Dentistry. Critical Reviews in Oral Biology \& Medicine, 12, 262-272. https://doi.org/10.1177/10454411010120030501

[14] Ioannidis, A., Gallucci, G.O., Jung, R.E., Borzangy, S., Hämmerle, C.H. and Benic, G.I. (2015) Titanium-Zirconium Narrow-Diameter versus Titanium Regular-Diameter Implants for Anterior and Premolar Single Crowns: 3-Year Results of a Randomized Controlled Clinical Study. Journal of Clinical Periodontology, 42, 1060-1070. https://doi.org/10.1111/jcpe.12468

[15] Moreira de Melo Jr., E.J. and Francischone, C.E. (2019) Three-Dimensional Finite Element Analysis of Two Angled Narrow-Diameter Implant Designs for an All-on-4 Prosthesis. Journal of Prosthetic Dentistry. (In Press) https://doi.org/10.1016/j.prosdent.2019.09.015

[16] Velasco-Ortega, E., Flichy-Fernández, A., Punset, M., Jiménez-Guerra, A., Manero, J.M. and Gil, J. (2019) Fracture and Fatigue of Titanium Narrow Dental Implants: New Trends in Order to Improve the Mechanical Response. Materials, 12, 3728. https://doi.org/10.3390/ma12223728

[17] Cordaro, L., Torsello, F., Mirisola Di Torresanto, V. and Rossini, C. (2006) Retrospective Evaluation of Mandibular Incisor Replacement with Narrow Neck Implants. Clinical Oral Implants Research, 17, 730-735. https://doi.org/10.1111/j.1600-0501.2006.01276.x

[18] Polizzi, G., Fabbro, S., Furri, M., Herrmann, I. and Squarzoni, S. (1999) Clinical Application of Narrow Brånemark System Implants for Single-Tooth Restorations. The International Journal of Oral \& Maxillofacial Implants, 14, 496-503.

[19] Romeo, E., Lops, D., Amorfini, L., Chiapasco, M., Ghisolfi, M. and Vogel, G. (2006) Clinical and Radiographic Evaluation of Small-Diameter (3.3- $\mathrm{mm}$ ) Implants Followed for 1-7 Years: A Longitudinal Study. Clinical Oral Implants Research, 17, 139-148. https://doi.org/10.1111/j.1600-0501.2005.01191.x

[20] Wadia, R. (2019) Narrow-Diameter Implants. British Dental Journal, 226, 575. https://doi.org/10.1038/s41415-019-0266-y

[21] Anitua, E., Errazquin, J.M., de Pedro, J., Barrio, P., Begoña, L. and Orive, G. (2010) 
Clinical Evaluation of Tiny ${ }^{\circledast}$ 2.5- and 3.0-mm Narrow-Diameter Implants as Definitive Implants in Different Clinical Situations: A Retrospective Cohort Study. European Journal of Oral Implantology, 3, 315-322.

[22] Arisan, V., Bölükbaşi, N., Ersanli, S. and Ozdemir, T. (2010) Evaluation of 316 Narrow-Diameter Implants Followed for 5-10 Years: A Clinical and Radiographic Retrospective Study. Clinical Oral Implants Research, 21, 296-307. https://doi.org/10.1111/j.1600-0501.2009.01840.x

[23] Froum, S.J., Shi, Y., Fisselier, F. and Cho, S.C. (2017) Long-Term Retrospective Evaluation of Success of Narrow-Diameter Implants in Esthetic Areas: A Consecutive Case Series with 3 to 14 Years Follow-Up. International Journal of Periodontics \& Restorative Dentistry, 37, 629-637. https://doi.org/10.11607/prd.3266

[24] Trbakovic, A., Bongenhielm, U. and Thor, A. (2018) A Clinical and Radiological Long-Term Follow-Up Study of Narrow-Diameter Implants in the Aesthetic Area. Clinical Implant Dentistry and Related Research, 20, 598-605.

https://doi.org/10.1111/cid.12627

[25] Pommer, B., Mailath-Pokorny, G., Haas, R., Buseniechner, D., Millesi, W. and Fürhauser, R. (2018) Extra-Short $(<7 \mathrm{~mm})$ and Extra-Narrow-Diameter $(<3.5 \mathrm{~mm})$ Implants: A Meta-Analytic Literature Review. European Journal of Oral Implantology, 11, S137-S146.

[26] Parize, H.N., Bohner, L.O.L., Gama, L.T., Porporatti, A.L., Mezzomo, L.A.M., Martin, W.C. and Gonçalves, T.M.S.V. (2019) Narrow-Diameter Implants in the Anterior Region: A Meta-Analysis. The International Journal of Oral \& Maxillofacial Implants, 34, 1347-1358. https://doi.org/10.11607/jomi.7526

[27] Yang, G., Chen, L., Gao, Y., Liu, H., Dong, H. and Mou, Y. (2019) Risk Factors and Reoperative Survival Rate of Failed Narrow-Diameter Implants in the Maxillary Anterior Region. Clinical Implant Dentistry and Related Research, 22, 29-41. $\underline{\text { https://doi.org/10.1111/cid.12867 }}$ 